\title{
Organizational Practice in the Heterolingual Archive
}

\section{Prática organizacional no arquivo heterolingual}

\author{
Michael J. Barany \\ Ph.D., history of science \\ University of Edinburgh \\ michael@mbarany.com
}

Recebido em: 21/04/2020

Aceito em: 21/04/2020

\section{Following the Sources}

I am an accidental global historian. When I began to train in earnest as a historian, I was interested in the politics, ideology, and social organization of modern mathematics. The mathematicians and mathematical institutions I knew were mostly European and North American, and their concerns appeared to be mostly local, national, or universal, skipping over the intermediate scales where the most trenchant challenges and concerns of global history lie. Because I did not set out to develop a global perspective on this mathematical history, I can give an unusually precise account of how the problem of international and global archives became central to my scholarship and came to dominate not just my research practice but my analytic perspective.

My conversion moment arrived as something of a historians' cliché. I had always been a little skeptical of historians who spoke of following their sources from their archives to questions and conclusions they had never contemplated in their initial formulation of their research topic. My own plan for my doctoral research focused on the postwar history of the theory of distributions in mathematical analysis. The theory was initially developed in the immediate wake of the Second World War by French mathematician Laurent Schwartz, a famously charismatic figure with pronounced political passions who helped define modern mathematics in and beyond France in the latter half of the twentieth century.

After developing and defending my dissertation prospectus and beginning to poke around in archives within a reasonable drive from Princeton, New Jersey - as far afield as the Rockefeller Archive Center, some 85 miles of congested freeway to the north-I secured a 
grant from the United States National Science Foundation to support a preliminary round of research abroad and set out for Paris to learn as much as I could about Schwartz's life, theory, and contexts. Initial returns were somewhat disappointing. For all his glamour and social connections, Schwartz left a remarkably thin paper trail in the decades of his life that most interested me, when he began to establish his theory and career. His personal archive was nearly devoid of letters and other documents from those years, and the institutional archives for the places where he started to make his mark were nearly as sparse.

At the suggestion of a friend and fellow graduate student, I made an appointment to visit the archives of the United Nations Educational Scientific and Cultural Organization (UNESCO) without expecting to find much of relevance to my project. UNESCO supported a variety of projects in computing and mathematics education, but the international organization's stake in theoretical mathematical research was understandably limited. It did not take long to call up every file in the card index associated with some variation of the term "mathematics." As the reading room's closing time approached, I lined up a final folder to examine before wrapping up for the day, on mathematics teaching in Argentina. The first page, on opening the folder, was a brief memorandum that included a familiar but unexpected name: "Prof. L. Schwartz de Paris."

That file brought me into a world of international exchanges and institutional negotiation that quickly became the center of my research and of my historical understanding of Schwartz, distributions, and twentieth century mathematics. It prompted me to change my approach to archives and evidence, ultimately turning a project based in a handful of North American and Western European repositories into one that drew from more than fifty collections across five continents. It also suggested a different way of reading and interpreting archival evidence that I have carried throughout the project, tracing what I will characterize here as organizational practice in the heterolingual archive.

\section{Mathematical Revolutions}

Before I became an accidental global historian, I was an accidental historian of science. I started my university education on a path to become a mathematician. In high school, a program run by the nearby state university let me speed through the basic curriculum and spend my last two years enrolled in the university's advanced mathematics courses. The professor for one of these courses decided that term to try out a textbook by sometime-distribution-theorist Robert Strichartz. The next year, I matriculated to Strichartz's university to study mathematics and, at his invitation, started by taking his own graduate course in mathematical analysis.

For the first lecture on the first morning of that course, Strichartz began by talking about Thomas Kuhn and the Structure of Scientific Revolutions. There were two twentieth-century revolutions in mathematical analysis, Strichartz asserted: Henri Lebesgue's revolution in the theory of integration at the turn of the century, and Schwartz's in the theory of differentiation (the converse of integration in calculus) at mid-century. The course would, broadly speaking, cover these respective revolutions in turn over its two semesters.

As it had for historians and philosophers of other sciences, Kuhn's account of scientific revolutions occasioned both excitement and skepticism among historians and philosophers of mathematics in the decades after its 1962 publication. For scholars of mathematics, it landed amidst a rich debate on the social and cultural bases of mathematical ideas and proofs, including landmark contributions by philosopher Imre Lakatos and mathematician Raymond Wilder to whose works Strichartz would later introduce me. While there was no consensus about the extent to which Kuhnian revolutions happened in mathematics, there was broad agreement that mathematics had a distinctive relationship to evidence, experiment, and demonstration that called for distinctive explanations.

I learned to see mathematical arguments as the product of mathematical communities that could determine and disagree about the validity or meaning of a proof or concept. These communities, I came to recognize, could disagree on political, ideological, and other grounds beyond the technical and academic concerns that animated debates about the foundations of mathematics and the proper methods of reasoning 
and demonstration. My undergraduate thesis took up a perennial topic for historians of mathematics, the early nineteenth century revolution in the foundations of mathematical analysis associated with another French mathematician, Augustin-Louis Cauchy, and its connection with the socio-political French Revolution of the late eighteenth century. My analysis made no use of archives and I was by no means a historian, but the problem of revolutions became a gateway for me from mathematics into the history of science.

\section{In the Heterolingual Archive}

I digested these debates about the history and philosophy of mathematics along with mathematics coursework while pursuing a parallel interest in critical literary theory, a field whose special presence at the university included an annual summer school headquartered in the old university presidential residence across a flower garden from the mathematics building. Through several courses on deconstruction and critical theories of translation and narrative, I explored how theories other than Kuhn's might explain what made mathematics different and what made it work. Among these, I learned from translation theorist Naoki Sakai about a distinction from his study of the history of Japanese language and literature between homolingual and heterolingual address. ${ }^{1}$

The distinction, roughly speaking, rests on how one understands a failure to communicate. Understood homolingually, the world of discourse is divided between distinct linguistic (typically national) communities. We presume that each language is transparently meaningful to those who share it, and we fail to communicate insofar as we do not understand the other's language. Homolingual translation changes discourse in one coherent language for another and is not necessary between speakers of the same language. Viewed heterolingually, however, we are always translating, always piecing together partial understandings of discourses that are fundamentally heterogeneous. Failure to communicate is the norm. By requiring continuous acts of translation, these ongoing failures bring interlocutors together as much as they separate them. The world of nations and of national languages is the product of, not the occasion for, translation.

On my doctoral research visit to Paris, I negotiated access to the UNESCO archives by introducing myself and my project by email to the archivist in the best formal French I could muster, exchanging a series of notes in the language to fix the time and conditions for my arrival. Greeting the archivist upon arrival, I learned that despite her perfectly French-appearing name and formal French emails, she was in fact an anglophone Canadian expatriate. Fellow anglophone researchers, I would later learn, greeted this discovery with equal surprise and relief. Our subsequent interactions were entirely in English, except for the few necessary consultations with the archives' director in the office adjoining the small reading room for visiting historians.

Roaming the halls of UNESCO's headquarters to and from the reading room, the coffee machine, and the cafeteria, I recognized a flurry of languages. There was a constant and visible dance of inferring the linguistic capabilities and preferences of one's interlocutor, of settling into a comfortable-enough accommodation that could involve speech and gestures in multiple idioms. Translation was everywhere, even between people ostensibly speaking the same language. Some languages were hegemonic-mainly French and English, in different ways-and there were plenty of failures of understanding. This was no polyglot utopia. But I was struck by a feeling of the heterolingual theory I had learned as an undergraduate coming alive as a kind of heterolingual practice.

Back in the reading room, the archival files pulsed with a cognate heterolingualism. As I wrote to my advisor back in Princeton, "UNESCO has given me a lot of practice at skimming dossiers in multiple languages ... Like at the UNESCO headquarters itself (today), most correspondents in the archive safely assumed their counterparts could basically figure out what they wrote in whatever language they were most comfortable in ..., so there are letters going out in French, being returned in Spanish, abstracted in English, drawing in

1 See "Introduction: Writing for Multiple Audiences and the Heterolingual Address," in N Sakai, Translation and Subjectivity: On 'Japan' and Cultural Nationalism (Minnesota, 1997), 1-17. 
criticisms in Portuguese." I had to learn, as best I could, to read like the bureaucrats and officials and mathematicians in the archives, making good-enough sense of a flurry of correspondence in multiple languages written with the assumption that some (even most) of their readers might not be fluent in the document's idiom. This gave me a useful empathy for my historical informants, and also a means of making my own meaning from a mass of files in languages where I was far from fluent.

Though historians are warmly welcomed and supported there, the UNESCO archives are, foremost, a working diplomatic repository organized around the work of UNESCO officers and staff in the present. This orientation affects how folders and reference books are arranged, indexed, preserved, and accessed. Archive staff regularly resorted to a mixture of tricks, hunches, rules-of-thumb, and guesswork to unearth potentially relevant materials. In one case these directed me to another building (with its own security protocols and reading room) on the supposition that my files of interest might have been folded in with later records stored elsewhere. Sometimes these led to dead ends, as with a hypothetical series of records that we ultimately guessed had been destroyed some years back in a fire. In retrospect, I came to see this archival practice as its own kind of institutional translation, converting archival regimes from the bureaucracy of an intergovernmental and transnational organization to those of historical scholarship, always partially and risking failure or misunderstanding. ${ }^{2}$

\section{Revisiting a Homolingual Archive}

My gleanings from UNESCO, particularly regarding international mathematical exchanges with Latin America, changed how I understood files I had seen before my departure at the Rockefeller Archive Center. The latter archive, in a converted Rockefeller mansion in a picturesque town outside of New York City, is a well-loved site of pilgrimage for modern historians of many stripes. Though built from the working archives of the Rockefeller Foundation and numerous other organizations and individuals whose papers are conserved there, the massive collections at the RAC primarily serve historical researchers, who are supported by an expert staff of archivists and an extensive research infrastructure.

The program and fellowship files I consulted over many visits to the RAC, though also deriving from large, internationally-oriented projects and organizations, reflected a somewhat different kind of bureaucratic and institutional practice from their UNESCO counterparts. The Rockefeller records of mid-century mathematics reflect a centralization of resources and responsibility, a wide-reaching system of gathering, recording, and making use of information, and a mass of copies, excerpts, and cross-references showing ongoing exchanges within and between program operations. Program officers' ways of thinking and acting were built into their files. Non-English documents received prompt translations, and in some files only the English translations survive. Foreign terms, structures, and systems, too, were translated by various means to more familiar reference points as they filtered through Rockefeller dossiers.

Rockefeller Foundation program officers prized local knowledge and flexibility, but they did so homolingually. Where they encountered differences, they did their best to render those differences in uniform terms that were compatible with their organizational practices. The science and scientists they supported were, as they saw them, fundamentally the same: coherent in their own contexts and translatable between other places and systems. Bureaucracies and their archives create historical subjects, assigning them roles and networks and itineraries, papering over many of the misunderstandings and indeterminacies that drove and challenged bureaucratic and archival activity along the way.

2 Translation has, of course, been a rich and durable metaphor for the history and sociology of scientific institutions. See the oft-cited S L Star and J R Griesemer, "Institutional Ecology, 'Translations' and Boundary Objects: Amateurs and Professionals in Berkeley's Museum of Vertebrate Zoology, 1907-39," Social Studies of Science 19, no. 3, 1989, 387-420; P Galison, Image and Logic: A Material Culture of Microphysics (Chicago, 1997), ch. 9. 
I came to appreciate this most vividly in the paper trail surrounding Uruguayan Communist mathematician José Luis Massera. ${ }^{3}$ I originally took note of his Rockefeller Foundation fellowship file for its striking pronouncements about Massera's politics, as well as the foundation's insistence on minimizing the effects of Massera's political activity and commitments on the administration and assessment of his visit to the United States. Massera's Rockefeller dossier is filled with surprises and adaptations, including a visa denial and a cross-continent move to address a scientific mismatch with his proposed mentor. Viewed through the paperwork, Massera and his Rockefeller counterparts basically understood each other and worked together to navigate a variety of obstacles.

To comprehend Massera's itinerary heterolingually would require piecing together correspondence from multiple archives, including his personal archive in Montevideo and the sprawling secret file assembled about him by the United States Federal Bureau of Investigation. Reading Massera through this wider archive showed how persistently misunderstood he was, and how much he himself misunderstood about his interlocutors and contexts. These misunderstandings could be just as decisive in his travels and relationships as the sequence of shifting understandings in his Rockefeller file.

\section{Crossing Itineraries}

While in Paris, I tried-with varying degrees of success-to pay a visit to every archive in or near the city that potentially held material related to my project. In many cases, I left with little to show for the visit in terms of documents I might cite, but added all the same to my experience navigating protocols of access and investigation in different archival settings. In other cases, as with UNESCO, I stumbled into an abundance of useful materials. Most visits contributed a small piece here or there to an emerging picture.

Those small pieces add up. After Paris, I developed a strategy of trying, wherever possible, to extend travel for conferences, research, or other purposes to include as many nearby archives as I could reasonably arrange, even when I did not expect to find much. I learned how to balance opening hours and transit schedules, as well as how to work around archives' respective rhythms and procedures for requesting and consulting files. When trying to get a sense of a discipline and its global contexts, there were few standout sources and every incentive to multiply impressions of the mass of routine paper traces. Changing technologies and archive policies for digital photography, in particular, vastly increased the range of sources I could consult in a single visit, making a notable difference even between the start and end of my doctoral research. On the kinds of research funds available to a doctoral student, even at a very well resourced department and university, opportunistic side-trips were an appealingly economical way to gain experience and source material.

When the Society for Social Studies of Science planned their 2014 annual meeting with their Latin American counterpart (ESOCITE) in Buenos Aires, I seized the chance and assembled a patchwork of grants to spend the month in South America, starting in Montevideo then continuing through Buenos Aires to São Paulo and then Rio de Janeiro. After my experience with the UNESCO archives in Paris-both the surprising finds and the apparent gaps in the Paris headquarters files-I had high hopes for UNESCO's Latin American headquarters in Montevideo. My command of Spanish was just solid enough to arrange a visit and explain my interests over email and telephone. I arrived to find that the Montevideo building operated with a much slimmer working archive, with virtually nothing from its early years. Protocols for centralizing records, in this case, had reinforced omissions in the historical evidence.

Rather, I found considerably more evidence of UNESCO's and other organizations' regional operations in the personal archives of mathematicians at the Universidad de la República a short walk away. Massera's papers enriched and complicated the picture of his correspondence with North American mathematicians

3 See especially Michael J. Barany, "The Officer's Three Names: the formal, familiar, and bureaucratic in the transnational history of scientific fellowships," in Krige (ed.), How Knowledge Moves: Writing the Transnational History of Science and Technology (Chicago, 2019), 254-280. 
and showed evidence of other international connections. Still richer was the archive of Massera's colleague (also a Rockefeller Foundation fellow), Rafael Laguardia, whose institution-building work and custom of retaining documents made for shelves full of valuable material.

Having worked my way through Laguardia's interactions with foundation and government officials and fellow mathematicians, I concluded by flipping through the mathematician's album of photographs. Such albums can add historical color to one's research, but for someone with my training (lacking the expertise to attempt a more sophisticated reading of photographic evidence) they did not tend to be nearly as revealing as a much less visually striking carbon-copy memorandum. This time, however, I turned a page and landed on a photograph of Laurent Schwartz-a widely-reproduced photograph I had seen before, typically implied to be from his early teaching career in France, but never with an attribution of its date or location. Jotted in pencil on the back of this specimen, by contrast, was the precise occasion of this famous image: Schwartz's visit to Montevideo as part of his UNESCO-sponsored Technical Assistance mission to Rio de Janeiro in 1952. As I would do in my own way six decades later, Schwartz was piecing together an opportunistic tour of the region, a foundation for longer-lasting ties with mathematicians in South America.

\section{Brokers and Translators}

In Buenos Aires, I hopped between a number of repositories. As I had begun doing in Princeton and Paris, I made sure to browse the libraries of institutions where my historical figures might have spent time or made connections, to look for theses, textbooks, journals, and other sources that may have circulated in my period of interest. These yielded some clues, but the 4S/ESOCITE conference ended up having a much more decisive effect on my research in South America than did my Buenos Aires archives. At the conference, through chance encounters, scheduling coincidences, and helpful introductions, I met a number of scholars (including this issue's guest editor) who would help me navigate the cities, institutions, archives, cultures, and languages for the rest of my itinerary.

While the 4S/ESOCITE conference sessions-especially those organized by anglophone scholars-mostly seemed to cleave along linguistic lines, my own session turned out to be a thrillingly heterolingual experience. Speakers presented and fielded questions in all three of the official conference languages (English, Spanish, and Portuguese), translating for each other and making do with partial understandings, circumlocutions, and hand gestures to find shared meaning when none of us could really be said to be confidently and fluently bilingual in the conference languages, much less trilingual. Learning I would be headed to Rio de Janeiro in a couple weeks, a fellow presenter arranged for me to speak at her institution-where I was also planning archival research, for which she suggested some additional files. Since I did not speak Portuguese, we decided I would be more likely to be understood in my decidedly unfluent Spanish than in my native English. I spent part of the intervening weeks translating my talk as best I could, and was rewarded with a delightful discussion prosecuted in approximate-Spanish by a room full of non-hispanophones.

These kinds of linguistic barriers and accommodations, while limiting in some respects, could be a resource for my research in other ways. Few of the mathematicians I studied were confident speakers of the dominant languages everywhere they traveled, and some even reflected on the experience of getting by with the help of colleagues and intermediaries while picking up bits and pieces of local idioms. Sensitized by my own experiences, I took greater notice of the heterogeneous linguistic dynamics of international travel and academic exchange, including the importance of brokers and translators who gave traveling scholars access to institutions and languages alike.

My heterogeneous introduction to archives in Brazil took place between Buenos Aires and Rio de Janeiro in São Paulo. Contacts from the Buenos Aires conference and other networking meant I was always accompanied by a local academic when accessing-or, in the case of a repository blocked by barricades from student demonstrations, failing to access-a variety of materials at the University of São Paulo. Continuing 
on to the exclusively lusophone State Archives near the end of my stay in the city, I found I could recognize enough of the administrative and linguistic patterns to register, request documents, and make sense of what I was seeing, but not enough to engage in the sorts of conversations and inquiries that make archive work most productive.

In Rio de Janeiro, I continued to rely on institutional and linguistic brokers to navigate the city and its archives. Like my historical subjects before me, I also took advantage of the lasting effects of English and French linguistic hegemony on the international institutions I visited, which put both the documents I consulted and the people who helped me access them on closer to a mutually functional linguistic footing with me. After a disappointing haul from its Argentine counterpart, I had low expectations for the Brazilian Foreign Ministry archives, but found evidence of a government much more actively involved in national mathematical affairs. These collections included documentation of Brazilian participation in International Congresses of Mathematicians and records of UNESCO exchanges-including Schwartz's from 1952-that complemented UNESCO's paper trail and dwarfed what was retained in UNESCO's South American headquarters.

As I had already observed elsewhere, there was a marked difference between archives organized with historical intent and those whose main function remained supporting current operations. For the latter, it was not always straightforward to find the people whose personal knowledge of idiosyncratic records could direct me to the documents that most interested me. On my initial visits to the Instituto de Matemática Pura e Aplicada, I had to content myself with browsing journals and old textbooks and lecture notes in the library, supplemented by brief conversations with a couple of the institute's mathematicians. It was not until my return to IMPA three years later, in conjunction with the International Congress of the History of Science and Technology, that my better-developed connections among historians yielded the right introductions to IMPA personnel who controlled access to an unpublicized closet containing a rich trove of letterbooks filled with correspondence and other records from the institute's early years.

\section{People and Institutions}

The close connections between problems of language and access in international archival research underscores, for me, the complex variety of personal activities and relationships that make up organizations and institutions at multiple scales. Institutional archives with various structures and orientations have been fundamental for my research, but diverse personal archives (often embedded in or alongside institutional ones) have been just as important sources of information about institutional dynamics and organizational practice. Rafael Laguardia's personal papers in Montevideo have been among my best sources for understanding United States-funded scientific exchanges involving South American mathematicians and institutions. Papers of individual mathematicians in the Harvard, Brown, and Copenhagen University archives have told me far more about the operations of international mathematical organizations than anything those organizations hold themselves.

The more a historical actor needed to piece together an understanding of another entity, the more this work of translation and comprehension is likely to be reflected in the papers they assembled and retained. Often, this took the form of relatively powerful and well-connected figures working to define or remake institutions. Unable to access the John Simon Guggenheim Memorial Foundation's records of their Latin American fellowship programs, I found key exchanges and records in the personal papers of Henry Allen Moe, the foundation's chief administrator. Sometimes, the lines between personal and institutional archives are blurred in historiographically significant ways: the layered entanglement in the archives of the Tata Institute of Fundamental Research in Bombay with the personal papers of its founding director Homi J. Bhabha show an individual who profoundly shaped but did not quite master every aspect of its operations.

Bhabha clashed consequentially with mathematician Damodar D. Kosambi, whose personal papers in New Delhi reflect a formidable figure sparring from a variety of positions and postures with powerful institutions. These latter papers, controlled by a library regulated by the Indian Ministry of Culture, required an 
intricate sequence of negotiations and certifications to access that reached from before my visa application to visit the country and extended past my actual research to further stamps and attestations required for my departure. This was, by a considerable margin, the greatest bureaucratic effort I have expended to date to access a single archival collection, but each archive's access procedures reflect something of its host's frameworks and assumptions. To research the workings of mid-century mathematics in India entailed engaging with the complex bureaucratic legacies of state and national government that, in many respects, reached back to the political contexts of the mathematicians and institutes I was studying. How many forms of identification, whether these must include a passport, what promises and affirmations one must sign, whether one must bring or wear gloves, how one must handle folders and boxes, and numerous other details and differences show what documents and access mean in local contexts.

Sometimes, as with the archives of the Brazilian Foreign Ministry, the documents of one organization contain information about the operations of other organizations that cannot be found in that organization's own archives. Mathematics departments archive their activities unevenly, and occasionally conserve remarkable records. One would not know it from the terse catalogue description, but the Harvard Mathematics Department files offer a far more comprehensive reckoning of the 1950 International Congress of Mathematicians, which it helped to host, than the archives of the American Mathematical Society (the Congress's principal host) or the International Mathematical Union. Such differences in record-keeping can be accidental, but can also show differences in organizational assumptions and structures that suggest where power and influence operated in practice. These, too, follow the personal dynamics of institutions and the disconnections they enable between formal authority and routine action, as well as the displacements and substitutions that allow multiple people and organizations to act meaningfully in concert.

\section{Translation and Contingency}

Researching global and international history across archives, institutions, countries, and languages is a process of encountering and accommodating many different kinds of partial understanding and misunderstanding. A vital part of my formation as a historian has been learning to navigate these differences while also appreciating them, in their irreducible difficulty, as resources for historical interpretation. Failures to understand a language or institution are not unique to historians in archives, and close attention to this aspect of research can help one recognize and empathize with parallel failures and obstacles encountered by one's historical subjects. Tracing and reconstructing historical facts can be a way of seeking and building historical empathy.

One animating concern for my analysis of mid-century mathematics has been the relationship between international institutions and internationally-shared knowledge. Following negotiations and translations through a diversity of archives has underscored the defining role of fragmentary knowledge, misunderstanding, and piecemeal translation to the simultaneous construction of institutions and theories. ${ }^{4}$ Mathematical knowledge and institutions depended on brokers and translators, on accommodations and compromises, on tentative efforts to work past and around the routine inaccessibility of matters of collective endeavor, whether that endeavor was meant to produce a theorem or a textbook or a conference or something else.

Foregrounding the failures and the continual adaptation and repair, a heterolingual view of archival research connects the practice of international and global inquiry in the present to the historical practices of international and global mathematics. Dwelling on my own challenges of translation, in their many linguistic and non-linguistic forms, sensitizes me to the ongoing effort and practical achievement of translation visible, directly and indirectly, in historical archives. This perspective also makes visible the contingent achievement of homolingual views - of mathematics, organizations, or archives - that collapse and naturalize distinctions and difficulties within communities of practice, understanding, documentation, and coordinated action.

4 Michael J. Barany, "Integration by Parts: Wordplay, Abuses of Language, and Modern Mathematical Theory on the Move," Historical Studies in the Natural Sciences 48, no. 3, 2018, 259-299. 
I write this conclusion from my home under state-enforced restrictions on movement during a pandemic that has shuttered libraries and archives around the world. These closures, one confidently hopes, are temporary, but they signal a more durable precariousness fundamental to the methods and infrastructures of global archival research. Tracing the connections, exchanges, and negotiations that defined an internationally interlinked past does not quite require retracing those same dynamics, but it nonetheless calls for parallel kinds of activity that recapitulate the past's challenges and contingencies. As obstacles to accessing far-flung archives change-sometimes falling away, sometimes emerging from new threats or circumstances-historians' access to vital resources for historical empathy change apace. Reflecting on archival practice matters not just for improving our understanding, but for cultivating fruitful misunderstanding, and for empathizing through that misunderstanding with the tenuous work of drawing global connections that historians share, in our own ways, with our subjects from the past. 